\title{
Digital Sovereignty and Participation in an Autocratic State: Designing an e-Petition System for Developing Countries
}

\author{
Silvia Lips \\ silvia.lips@taltech.ee \\ Information Systems Group, Tallinn \\ University of Technology \\ Tallinn, Estonia
}

\author{
Rozha K. Ahmed \\ rozha.ahmed@taltech.ee \\ Information Systems Group, Tallinn \\ University of Technology \\ Tallinn, Estonia
}

\author{
Khayyam Zulfigarzada \\ khayyam.zulfigarzada@taltech.ee \\ Information Systems Group, Tallinn \\ University of Technology \\ Tallinn, Estonia
}

\author{
Robert Krimmer \\ robert.krimmer@ut.ee \\ Johan Skytte Institute of Political \\ Studies, University of Tartu \\ Tartu, Estonia
}

\author{
Dirk Draheim \\ dirk.draheim@taltech.ee \\ Information Systems Group, Tallinn \\ University of Technology \\ Tallinn, Estonia
}

Research (DG.O'21), June 09-11, 2021, Omaha, NE, USA. ACM, New York, NY, USA, 9 pages. https://doi.org/10.1145/3463677.3463706

\begin{abstract}
Establishing a sustainable citizens-government dialogue is a crucial topic on the agenda of many countries. E-petition systems are among the most popular and effective tools for establishing a responsive and effective dialog between governments and citizens. E-petition systems mitigate the gap between citizens and government authorities and contribute to the empowerment of citizens. This study aims to determine how to increase citizens' participation in decision-making processes through the case of an e-petition system in Azerbaijan. The research employs a mixed method of qualitative and quantitative data collection methods within a case study design. Data were collected from a triangulation of multiple sources, i.e., interviews with state authorities and online survey among the citizens of Azerbaijan. Additionally, we reviewed experiences from other countries that introduced e-petition systems, in order to better understand the success factors of and obstacles to launching e-petition systems, with a particular focus on the needs of developing countries. The outcome of this study is a proposed design of an e-petition system model that can be considered in developing countries.
\end{abstract}

\section{CCS CONCEPTS}

- Information systems $\rightarrow$ Computing platforms.

\section{KEYWORDS}

e-petition, e-participation, e-democracy, citizens empowerment

\section{ACM Reference Format:}

Silvia Lips, Rozha K. Ahmed, Khayyam Zulfigarzada, Robert Krimmer, and Dirk Draheim. 2021. Digital Sovereignty and Participation in an Autocratic State: Designing an e-Petition System for Developing Countries. In DG.O2021: The 22nd Annual International Conference on Digital Government

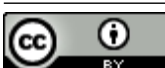

This work is licensed under a Creative Commons Attribution International 4.0 License.

DG.O'21, June 09-11, 2021, Omaha, NE, USA

(C) 2021 Copyright held by the owner/author(s).

ACM ISBN 978-1-4503-8492-6/21/06

https://doi.org/10.1145/3463677.3463706

\section{INTRODUCTION}

In a number of countries around the world, regardless of the social and economic conditions, public dissatisfaction is one of the fastgrowing internal problems $[6,7]$. In some societies, the level of public dissatisfaction reaches a worrying level and very often leads to significant consequences $[6,15]$. Citizens are disgruntled with the quality of work of state and regional government authorities that can result into distrust [20].

Citizens may become frustrated, when their complaints and appeals do not reach relevant authorities, i.e., if we encounter a lack of official and effective communication between the government and its citizens or lack of motivation from the authorities side to meet citizens expectations [8]. Too often, citizens' request for support and attention remain unheeded. In a society where the government keeps itself away from its citizens, and where citizens cannot interact with the officials at an appropriate level, an atmosphere of hopelessness and mistrust to the government can emerge. Gradually, people become reluctant to participate in decision-making processes, as they loose interest and do not see themselves as stakeholders who can influence state decisions.

Unfortunately, very often in developing countries there is an insufficient level of communication between the state and its citizens. In the case of Azerbaijan, studies have shown that most of the population of Azerbaijan is dissatisfied with the current level of dialogue and is experiencing problems to express their opinion to the relevant state structures and authorities ${ }^{1}[1]$. Although the Azerbaijan government is enormously interested in raising e-government technologies in the country, which shows, e.g., in the establishment of an "E-government Development Center" [23, 27]. However, in 2018, the problem of lack of dialog between citizens and government in Azerbaijan still exists. Such problems are plausible, as it is known from research of authors like Gustav Lidén, that autocratic countries regularly achieve lower scores in e-participation and e-democracy than countries that are more democratic [17], p. $706 f f$.

${ }^{1}$ Bertelsmann Stiftung's Transformation Index (BTI) 2018. Available: https://www.ecoi.net/en/file/local/1427383/488339_en.pdf 
Considering these aspects, this research aims to propose and design an e-petition system for developing countries using Azerbaijan as a case study. The main research question is the following:

- How to design an e-petition system for developing countries enabling additional channel for citizen's participation in public decision making?

It is important to consider relevant vital social, political and technical conditions in the country. Regarding the methodology, this research employed a case study design through a mixed approach of qualitative and quantitative data collection methods. The authors analyzed the current environment in the country and whether the country is able to ensure the preconditions for successfully implementing an e-petition system. We used different sources for data collection. From this analysis, it turned out that a major success factor is in the government authorities' interest into and usage of the system. The authors conducted several interviews with public officials from different Azerbaijani authorities. Moreover, citizen views were considered as significant measure through an online survey.

Sect. 2 provides an overview of relevant efforts on e-petition systems in other couturiers. Sect. 3 presents the research methodology, together with an overview of the case of Azerbaijan, and data collection procedure. Sect. 4 presents the findings of the analysis. Then, Sect. 5 proposes an e-petition system model for Azerbaijan. Sect. 6 presents limitations and future direction of the study. The paper finishes with a conclusion in Sect. 7.

\section{LITERATURE REVIEW}

Several countries in the world already benefit from the implementation of e-petition platforms [10]. Positive experiences of those countries have shown that with a smart and comprehensive approach, such tools can yield very good results [9].

The main goal of this research is to propose a suitable e-petition system model for developing countries that can help to increase citizens' participation and engagement in the decision-making process. Undoubtedly, in service of this case, international experience should be considered and studied. It is important to use the experience of other countries to understand what aspects contribute to the successful functioning of e-petition platforms, which obstacles might interfere with them and how to overcome those [5]. In this section, the authors focus on the most important structural parts and different examples (both successful and unsuccessful) in order to understand how to build a model that will be suitable for Azerbaijan and could be used also in other developing countries [9].

For example, Ukraine has introduced a de-centralized web-based platform through which petitions can be signed. All petitions that collect more than 25,000 signatures within 3 months are be discussed by the government authorities [14]. However, the e-petition platform is not very popular and the Ukrainian Parliament's petitions are practically not functional [21].

Similarly, Moldova implemented a web-based centralized environment where petitions are submitted via the government web-site and signed using e-signatures[14]. The e-participation in Moldova is low and political context for e-petition activities rather unfavorable. There is lack of trust towards the authorities and low technological awareness. Instead of using e-petition environment provided by government, the enthusiasts prefer organising separate campaigns [13].

The United Kingdom also implemented a web-based centralized environment where British citizens or UK residents can initiate petitions and government respond to petitions that get at least 10,000 signatures $[19]^{2}$. The example of UK can be considered as successful as, since 2015, electronic petitions in UK collected a total of 50 million signatures; and the process of signing petitions has become the second most popular form of political activity after voting[4].

In Estonia, several web-based e-petition platforms exits that allow for proposing ideas and collecting signatures in support of proposed ideas, for expressing opinions on legal drafts, as well as for searching legal acts and strategies. One of these examples is web-based e-petition platform osale.ee ${ }^{3}$. However, this particular example in the field of e-petition field cannot be considered as successful [24].

The United States (US) e-petition system is considered practical as compared to other web-based application systems in the country. In the system, it is possible to continue collecting signatures after submitting a petition to the governmental authorities[3]. In 2005, the German federal parliament (Deutscher Bundestag) launched an online e-petition platform, that allows for signing petitions and to discuss them in a forum[22]. According to [18], the German system is dominated by small number of high-volume petitions[11] and petitioners belong to the younger generation. In addition, it is important to mention that among the younger generation, different social media platforms play significant role in terms of sociopolitical engagement[2].

The success of e-petition systems has been influenced by many aspects specific to each of the several different countries such as technical equipment of the country, technology awareness of the people, the level of education, cultural and historical background, whether the concept of e-petition is familiar to the public etc. [10] The authors tried to focus not only on examples of developed western countries but also on the experience of countries that have a cultural background and level of development that are more similar to those of Azerbaijan.

Based on the literature review, it is possible to say that there is no single model suitable for immediate adoption in developing countries. However, it is possible to use elements and practice from previously described countries to design an e-petition system model more suitable for developing countries.

\section{RESEARCH APPROACH}

This research adopted a case study strategy, as it conducts an indepth investigation of a contemporary phenomenon within its real-life context [25]. A case study is suited when the boundaries between a phenomenon and a context are not completely clear, and whenever there is a lack of earlier studies to estimate the outcome. Considering that, this strategy is well-suited for the case of Azerbaijan to investigate the current state and present a sustainable

\footnotetext{
${ }^{2}$ https://petition.parliament.uk

${ }^{3}$ www.osale.ee
} 
and effective model of e-petition system as a first engagement platform between citizen and government in Azerbaijan.

\subsection{The Case of Azerbaijan}

Azerbaijan is located in the crossroads between Eastern Europe and Western Asia. Being a former soviet and developing country, Azerbaijan tries not to stay behind in a sphere of technological development, including the e-government sector. The country has successfully implemented several e-government projects and keeps showing rising interest in this field [26].

Currently, Azerbaijan faces the problem of a lack of a dialog between its citizens and the government. Even though the Azerbaijani government shows interest in e-government, yet, no e-democracy projects have been launched in the country.

It is clear that before launching a similar system in Azerbaijan, the government should have a clear vision of how to implement it correctly. It is important to consider all vital social, political and technical conditions in the country to ensure all necessary conditions for making the system successful. Such tool as e-petition system can help to solve a number of problems related to citizen participation in decision making process for the case of Azerbaijan.

\subsection{Data Collection}

Given the nature the research, it was decided to use mixed of qualitative and quantitative data collection methods. Investigating the problem of proposing a successful e-petition system model, requires a complex and comprehensive approach and therefore using both qualitative and quantitative data collection methods helps to get a better overview and understanding of the issue. Supported by reviewing existing relevant literature.

Considering that the ultimate goal of the research is to find an answer about how to design the most suitable e-petition system for developing countries similar to Azerbaijan, the source and process of data collection for the research can be divided into three groups.

3.2.1 Qualitative Method - Interviews. The state agencies play a significant role in the successful implementation of e-petition systems, as they cannot function without proper support of state structures. Regarding the attitude of state structures towards launching such platform, the authors conducted four interviews with official representatives of government bodies of various fields. The interviewees were chosen according to the sector of their organization. The authors focused mainly on sectors that interact with the citizens on a regular basis and provide services that have a crucial influence on the daily life of citizens: public transportation, education, social protection, and finance. All interviewees were informed about the purpose of the interview and the overall research processes. The interview were composed of 12 questions.

The interviewees have been:

- The Head of the Sumgayit Transport Agency under the Sumgayit city executive power from The Public transportation services.

- The deputy head of the Regional Financial Settlement Center No. 1 under the Ministry of Education.

- The leading adviser of the social service sector from the Absheron regional branch of the Ministry of Labor and Social Protection of Population.
- The leading Specialist from the ortgage and Credit Guarantee Fund of the Republic of Azerbaijan.

3.2.2 Quantitative Method-Online Survey. Considering the specifics and nature of this kind of systems there is a need to understand the citizens' view and expectations towards the e-petition system. A mass online survey is a fast and affordable way of collecting data and covering a broad number of respondents. The target group of the survey have been citizens of Azerbaijan, no matter of the social status, occupation, gender, and other aspects, as the system aims to be equally accessible for citizens. The survey has been conducted through the internet and spread among the population via social media channels. As already reflected from the literature review, technological awareness is one of the pre-conditions of the successful implementation of the e-petition system. Therefore, people who are already able to participate in the online survey, provide valuable input of their expectations towards the e-petition system being at the same time potential users in future.

264 citizens took part in the survey. The survey was composed out of 15 questions. Questionnaire was divided into three parts. The questions in the first part mainly aimed to clarify the purpose, frequency, and level of internet use among the participants. In the second part of the survey requesting sharing participants experience on the current situation of the dialogue between citizens and the government and their personal views and expectations about epetition portal. The third part related to the model and functionality of the system to understand the preferences of potential users.

3.2.3 Document Analysis. Another significant source of data is positive as well as negative examples and experience of other countries that have already launched an e-petition platform. Therefore, we analysed different data sources (reports, scientific literature etc.) of different countries. In Estonian case we even contacted osale.ee team to receive written feedback from the system implementation. It is crucial to analyse different documentary sources to understand what aspects affect successful functioning of e-petition platforms, which obstacles might interfere and how to overcome them. International experience is also valuable especially considering the fact that this research is new for Azerbaijan and there are no materials related to e-participation tools in the particular country context.

Figure 1 presents the current research approach and data sources.

\subsection{Validity Check}

The four criteria of validity judgment such as, construct validity, internal validity, external validity, and reliability in [25], were considered as an essential part of the study to assure the quality of research design.

- Construct validity is achieved through using a triangulation of multiple data sources such as interview, survey and document analysis to strengthen the validity of the information.

- Internal validity is more concerned with finding the causal relationship between outcomes and treatment [25]. As this current case study research is limited to only investigate the state and propose an effective model, it might be possible in further studies to explore the causal relationship.

- External validity is to ensure the generalization of the results. Authors provided detailed procedure of the research. 


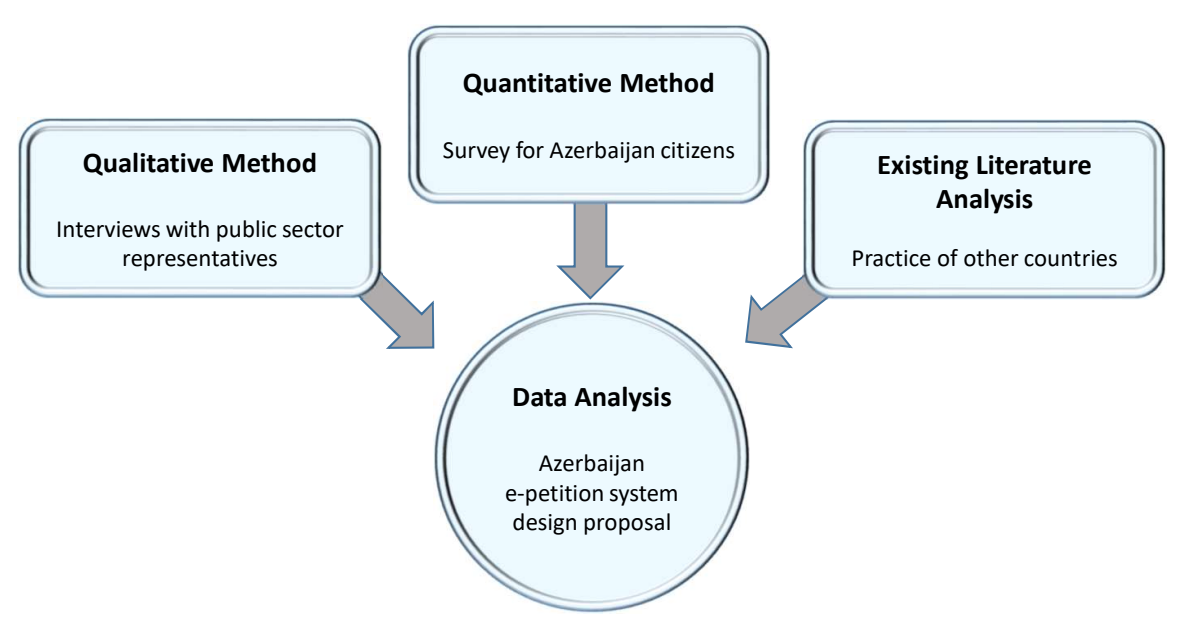

Figure 1: Research approach and data sources

Literature review and later document analysis showed that autocratic states face similar challenges with regards the e-petition systems. Therefore authors believe that the result can be generalized by producing the same process, in specific, for developing couturiers with a similar environment as Azerbaijan.

- Reliability is relevant to the ability of replicating the same procedure by different researchers and producing the same results. To ensure reliability of the research, authors created a case study protocol and documented all the procedures in the database.

\section{FINDINGS}

This section describes outcomes of the interviews and online survey. Based on this data it is possible to design and propose the most suitable and effective e-petition model for Azerbaijan that could be applicable also in other developing countries.

\subsection{Interview Results}

Four Azerbaijani state authorities were interviewed in order to understand their attitude towards the idea of implementing an e-petition system in Azerbaijan. It was important to understand whether they support the idea and would be ready to cooperate if the platform will be implemented.

The first two questions of the interviews were related to the functionality of the state organizations where interviewees were working and what services their orgnizations provide to the citizens. Interviewees described briefly the functionalities and roles of those bodies and also described the type and delivery-process of the services. Interviewees were also asked to evaluate the level of communication with the citizens in their organization. All respondents stated that the level of communication with citizens is at a very good level. Only one interviewee noted that he would prefer to increase the scale and audience of communication with citizens. The interviewee declared that at the moment, communication is mainly based on the requests from individuals, but the nature of the service that they provide requires in his opinion communication at the level of large groups of people since the requests are identical in most of the cases. Grouped requests would facilitate the work and save resources of the organisation. Interviewees noted that currently they use hot-lines and e-mails as communication channels with the citizens and they are always open for the appointments. One interviewee stated that they use electronic platform to communicate within the ministry with the other agencies under the jurisdiction of the same ministry as well as receive requests from the citizens and respond to them. All respondents stated that they consider these channels to be quite effective, but at the same time, they would not mind any improvements and the introduction of new ones.

Regarding the availability, feedback mechanism which could measure whether the citizens are satisfied with the service they provide, two interviewees admitted that they do not have any feedback mechanism. The rest two interviewees claimed that they call the customers after solving their issue and ask whether they were satisfied by the provided service or not. All respondents agree with the statement that high-quality communication favorably affects the quality of work of the organization and its reputation in the society. Moreover, one of the respondents even said that a good quality dialogue with citizens will give them a sense of security and strengthen their trust towards the government. This issue, in turn, depends also on the allocation of funds for this organization from the state budget.

Three out of four respondents had information on the experience of countries that have implemented electronic participation and e-petition portals. All four interviewees declared that they would like to have similar system implemented in Azerbaijan.

Respondents brought out following benefits with regards to the e-petition platform:

- The e-petition system helps to identify the most acute and important problems in the society and therefore authorities primarily can focus on the most urgent ones. 
- The e-petition system helps citizens to inform authorities about their problems and establishes two-way communication between the citizens and authorities.People often prefer to complain to each other rather than to forward their complaints to the appropriate authority. This, in turn, harms the organization's reputation, without even giving it a chance to find out about the problem and try to solve it.

- The e-petition platform can also be used for legislative discussions and for conducting mass surveys among the population. This option would be very beneficial for government organizations in terms of cost-saving.

- A large number of signatures collected via e-petition system indicates clearly the seriousness of a problem in the society If an organization needs additional funding, the process of requesting funds from the state budget will be much easier.

- The existence of such system can lead to the strengthening of civil society in a country. Citizens will more actively take part in the decision-making process. They understand better their importance and responsibility in these processes.

Finally, all respondents expressed their support and interest towards the idea and stated that if such system will be launched in Azerbaijan they would definitely use it. Interviewees also expressed their advice and recommendations regarding how they would like to see the e-petition platform. Two of them recommended that there should be a certain working group that would check the feasibility of the petitions before sending them to the appropriate authority, as well as distribute the petitions to the relevant state bodies as citizens can experience difficulties by doing it themselves. One interviewee suggested that petitions with a large number of votes should be discussed in the parliament. Based on the interviews it is possible to bring out following key findings:

- Government officials in Azerbaijan are aware of the phenomenon of electronic petitions. They have an understanding how the e-petition system is functioning and what benefits and values it can bring to the country.

- Officials consider the current level of dialog and quality of communication channels satisfactory. But at the same time, they accept that the platform of e-petitions would certainly be able to take the dialogue to a new level.

- Government officials are tech-savvy enough to collaborate with the e-petition portal, as they already use special software and internal e-portals on their workflows.

- There is a lack of feedback mechanism. In most cases, state authorities do not receive any feedback from the society regarding the service(s) they provide.

- Government officials are very enthusiastic regarding the idea of implementing such system in the country. They are open for cooperation.

\subsection{Survey Results}

A web-based survey was conduced for understanding citizen's attitude regarding the potential e-petition system. As the survey was spread through the Internet, only people who had an access to the Internet could express their opinion. Therefore, the survey does not cover the full spectrum of the population. However, at the same time, it is obvious that only people with an Internet access are able to take part of different ICT initiatives.

The survey was actively promoted and open for participation during a period of 3 weeks. During this period 264 respondents took part of the survey. Respondents were asked 15 questions and it was possible to share their own views or suggestions regarding the e-petition system. The survey was divided into 3 parts: general information about the respondent, respondent's views on the current situation of the dialogue between citizens and the government and his/her personal views and expectations towards the e-petition system.

$78.4 \%$ of the respondents were $18-29$ years old, $17,8 \% 30-45$ years old and respondents under 18 together with respondents 46 and up accounted for $3,8 \%$ of the total amount of respondents.

Rather high percentage (45.8\%) of the respondents had enough skills for using such comparatively complex e-services such as ebanking and e-shopping. $27.3 \%$ of the respondents outlined that they work in digital space, therefore they can use the Internet on a professional level. $24.2 \%$ responded that their skills are limited to finding information they need.

Survey respondents indicated that they use the Internet usually to find some information, for entertainment and for the communication purposes. $50 \%$ percent of the respondents said that they often use the Internet to pay utility bills, taxes etc. To the question if they ever heard or used any public e-services before, $46.6 \%$ respondents answered "yes, but not on regular basis" and $21.2 \%$ said that they use regularly e-services that exist in the country. At the same time $21.2 \%$ responded that they are aware of the e-services but have never used them before. $11 \%$ of respondents claimed that they have never heard about such services and therefore have not used any public e-services.

Most citizens believe that responsiveness of the government depends on how big is the problem for the society. Almost $30 \%$ of the respondents claimed that there is no dialogue between the government and citizens at all. $6.8 \%$ of the respondents did not know how to contact with the government authorities. Only $18.2 \%$ of citizens believe that the citizens-government dialogue is on a good level and government bodies respond to the citizens' requests.

Most respondents said that they use the hot-lines of the ministries as the main channel to communicate with them. The second most popular method according to the respondents is sending emails and applications through the official websites of the authorities. $12.5 \%$ of citizens have not even tried to contact the authorities, as their previous experience has shown that this is completely useless. Almost the same percentage of citizens declared that they always try to get an appointment and meet the officials. The left $20 \%$ of the respondents have never tried to contact the officials, as they have not had any necessity for this.

Slightly more than half of the respondents said that if e-petition platform will be launched in Azerbaijan, they will definitely use it. $37.9 \%$ said that they will use it only if somebody explains how to use it, first. Only $8 \%$ were skeptical and said that they would not use the e-petition platform since they do not believe in its effectiveness.

Citizens of Azerbaijan are aware of the existence of electronic petitions as a phenomenon. Some respondents even indicated that they 
had previously signed petitions on a platform such as Change.org, which is quite popular in Azerbaijan. Only one-third of respondents admitted that they have never heard about such platforms before. More than half of the respondents have optimistic views on the system and believe that it can solve number of problems and take citizen-government dialogue to the next level. $16 \%$ of respondents are skeptical and do not find implementing an e-petition system as a good idea and $10 \%$ think that the system will not receive a proper level of support and cooperation from the authorities.

In order to follow the new petitions, citizens would like the epetition portal to have its own pages in social network(s). In their opinion, it will be easier to stay informed about the petitions and also share them with friends. Many respondents supported the idea of sending the most popular and fast-growing petitions to their e-mail addresses.

Regarding the issue of registration and authorization procedure, most citizens said that they would like to open a personal account in the e-petition platform. They do not mind sharing necessary data for this. A little more than $30 \%$ percent of respondents would like to use their mobile ID for this. When citizens were asked whether they want their name to be displayed under the signed petitions, $56 \%$ percent of the respondents did not see any problem in that. $35.2 \%$ of the respondents wanted to have a function that allows them to decide whether to display their name or not. Only $9.8 \%$ of the respondents preferred to remain anonymous.

Respondents supported the idea of publishing state readings, government documents and other related information on the $\mathrm{e}$ petition platform. Citizens also showed a positive attitude towards the participation in legislation draft discussions or in mass surveys conducted by the government bodies.

The survey showed that if the e-petition platform will be launched in Azerbaijan, citizens will show interest and support it. Internet users would be capable enough to use such kind of platform as most of them already use periodically e-government and other electronic services. Survey results concluded recommendations from the respondents how they would like to see the e-petition platform from the design and functionality perspective.

\section{DISCUSSION}

Findings presented that citizens and government officials show quite positive attitude towards the idea of launching an electronic petition system in the country. The vast majority of the survey participants had very optimistic views and expectations towards the e-petition system. An interesting detail was that despite the fact that the majority of the population declares that the level of dialogue with government bodies is low, government officials believe that the dialogue between their authorities and the population is on a fairly good level. At the same time, it should be noted that government officials accept the need for improvement and expansion of current communication channels.

Azerbaijan has the competence and experienced people to implement this kind of system and related public e-services. State authorities and institutions are sufficiently equipped with ICT infrastructure and use Internet technologies on a daily basis as a vital part of their workflows. Government officials are tech-savvy, experienced, and trained enough to use different ICT tools necessary for the e-petition system implementation.

Regarding the digital literacy and readiness of the population, according to the international reports, it is at a satisfactory level $[12,16,26]$. Most of the population is actively using the Internet, including public e-services and a number of other digital services. Regarding the country's technical readiness for introducing an electronic petition system, report outcomes from relevant international organizations are also quite positive ${ }^{4}$.

Despite the existing difference in the Internet usage and digital literacy between urban and rural populations, the country's technical capabilities are satisfactory for introducing this type of system in Azerbaijan [26]. Such a difference been rural regions and cities is typical not only for Azerbaijan but also for most countries in the world.

\section{1 e-Petition Design Proposal}

Existing literature analysis and suggestions from the interviewed state officials clearly showed that an e-petition committee is a necessary part of a well functioning e-petition system. The Committee plays a role of an intermediary body that coordinates the interaction of the citizens with the relevant state bodies through the e-petition platform. The Azerbaijani e-petition committee may comprise of members of the parliament, similar to the German model. But authors believe, that it may also be controlled by a separate body such as the E-Gov Development Center of Azerbaijan republic ${ }^{5}$. The reason for this is the presence of specialists who are more likely aware of the functioning principles of such systems. In addition, it is important to examine and correct periodically existing errors in different functionalities of the e-petition platform. The most competent authority capable of doing this is "E-Gov Development Center". Therefore, it would be reasonable if the work of the committee, as well as the research and technical works related to the system, would be carried out by that institution. Authors believe that at the initial stage of the e-petition system implementation the petitions should be sent only to the state authorities. Based on the existing literature and practice analysis, in some of the countries petitions are discussed on a parliamentary level after collecting high number of signatures. Authors do not consider such model viable for Azerbaijan, at least not in the initial phase because it slows down the system implementation speed.

The main operations of the e-petition system considered for Azerbaijan are presented as follows.

- Account creation/authorisation. In order to sign the petition the user should create an account by providing following data: full name, phone number, e-mail address, physical address, personal identification code and postcode.

- Creation of the petition. The applicant should choose laconic and attractive name for the petition in order to engage more people. Then a wide description of the petition should be entered using well understandable language. It is important to indicate clearly the problems, explain the proposal,

\footnotetext{
${ }^{4}$ United Nations e-Government Survey 2020

${ }^{5}$ E-Gov Development Center. Available: https://www.digital.gov.az/en
} 


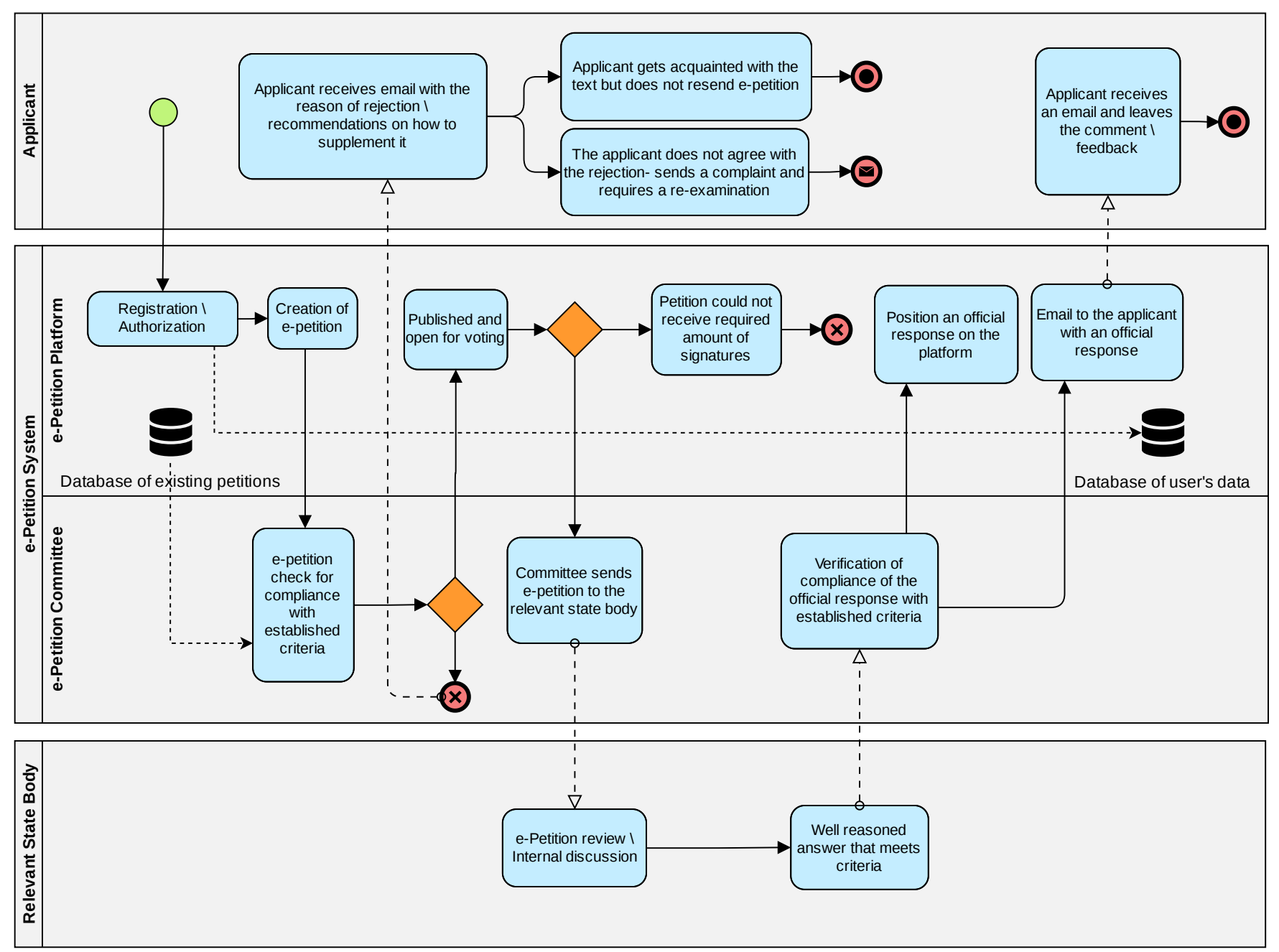

Figure 2: Proposed e-petition model

and what the applicant expects from the state authority. The reference data attached to the petition is welcome.

- Proceeding the e-petition. Compliance of the submitted e-petition and also the absence of identical petitions in the system is checked. After that, the petition is put to a universal vote for a 2 month period. The form of the published e-petition reflects following information: full name of the applicant, the petition text, the classification of the topic, reference materials and the number of signatories. Under the e-petition form, from the moment of its publication, a forum opens where citizens can discuss the petition details and attach additional reference materials.

- Delivering e-petition to the relevant state body and receiving a response. Petitions that receive 5,000 votes will be sent to the appropriate authority. The answer with regards to the e-petition shall be provided by the authority within 30 days. The petition committee monitors meeting the deadlines and also checks if the response meets to the agreed criteria or not. The state authority should explain its answer in an easy understandable language. The official response will be published on the web platform and sent to the main applicant(s) by e-mail.

Figure 2 reflects the work process of the e-petition system designed for Azerbaijan.

\section{RESEARCH LIMITATIONS AND FUTURE DIRECTIONS}

This research is one of the first of its kind conducted in Azerbaijan to address the topic of e-participation and e-democracy technologies. Current study can be considered as a starting point for a number of further studies aiming to resolve democratic issues and sociopolitical problems through the introduction of the e-democracy tools like e-petition systems not only in Azerbaijan but other similar countries.

This research is a pathway for further researches in Azerbaijan addressing the topics and problems that have not been under discussion before. The authors suggests not only to focus on the 
simplification and improvement of the public services provision processes but also on the involvement of the population in the public administration processes. Before actual launching of the e-petition system, a number of additional studies in this direction from different perspectives are necessary.

Moreover, the research approach of this study can be applied to investigate the practices of other developing and autocratic countries. Future research directions include comparison and analysis of different countries readiness to adopt an e-petition system.

From the limitations point of view it is likely that the results presented in this research may not cover all the e-petition systems implementation related aspects. Due to the high complexity of the epetition system implementation process in the autocratic countries, this research can not give an exact and detailed description of all procedural related aspects. For example, issues related to the compliance framework, different deadlines and response times inside the process, required number of signatures etc. require separate studies and analysis.

Another limitations of the study is related to the survey and interview participants. It is hard to affirm that the results of the survey reflect the views and opinions of the entire population of the country. Only those citizens, who had an access to the Internet at a moment of the survey promotion, were able to take part of the survey.

It should also be noted that $78 \%$ of the respondents were aged 19-29 and the results of the survey to a greater extent reflect mostly views and opinions of this particular age group. Therefore, it is important to study other groups in more detail in the future. However, proposed e-petition model is just one additional way to enable communication with the government authorities. Therefore, current focus group is sufficient to make first steps in this field.

\section{CONCLUSION}

Despite the fact that e-petition systems are a relatively recent phenomenon, they are gaining popularity and are already considered an effective tool for communication and cooperation between citizens and the state, especially in developing countries. Therefore, we investigated how to design an e-petition system for developing countries similar to Azerbaijan, enabling an additional channel for citizens' participation in public decision making. The focus was to find out what benefits such a system could bring and whether the country fulfills all the necessary conditions for launching such kind of system. In that endeavour, it was also important to study the experience of different countries that launched similar systems and to identify the key factors and processes that positively resp. negatively influenced the success of these projects.

The question of what kind of barriers and difficulties might arise when an e-petition system is launched in the country, and how the population and government agencies accept it, was fundamental within this research. To answer these questions, and in order to design a model of e-petition systems for developing countries, we analyzed international experience, spread a survey among the population of Azerbaijan, and conducted four in-depth interviews with government officials. The results were positive, i.e., a large majority of citizens participating in the interviews expressed interest and willingness to take an active part if a an e-petition system would be implemented. A similar feedback was received from civil servants, who also declared their readiness and support. We also found indicators that both in technical terms and in terms of digital literacy of the population, according to the current capacity of the country, Azerbaijan would be able to launch an e-petition system.

Based on our analysis, we designed and proposed an e-petition system model for Azerbaijan that can be used also in other countries with similar background. With this study, we explored the possibility of introducing an e-petition tool in Azerbaijan and, hopefully, entail a number of other studies in this area that help in the implementation of e-participation projects in other developing countries.

\section{ACKNOWLEDGMENTS}

The work of Robert Krimmer was supported in parts by European Union's Horizon 2020 research and innovation programme under grant agreement No 857622 .

\section{REFERENCES}

[1] Safura Aliyeva. 2021. Civic Engagement in Azerbaijan. International fournal of Civil Service Reform and Practice 5, 2 (2021).

[2] Airi-Alina Allaste and Kari Saari. 2020. Social Media and Participation in Different Socio-political Contexts: Cases of Estonia and Finland. Young 28, 2 (2020), 138156.

[3] Lyudmila Bershadskaya, Andrei Chugunov, and Dmitrii Trutnev. 2013. e-Participation Development: a Comparative Study of the Russian, USA and UK e-Petition Initiatives. In Proceedings of ICEGOV'13 - the 7th International Conference on Theory and Practice of Electronic Governance. 73-76.

[4] Jack Blumenau. 2020. Online Activism and Dyadic Representation: Evidence from the UK e-Petition System. Legislative Studies Quarterly July (2020).

[5] Knud Böhle and Ulrich Riehm. 2013. e-Petition Systems and Political Participation: About Institutional Challenges and Democratic Opportunities. First Monday 18, 7 (2013).

[6] Lisanne de Blok, Atle Haugsgjerd, and Staffan Kumlin. 2020. Increasingly Connected? Political Distrust and Dissatisfaction with Public Services in Europe, 2008-2016. In Welfare State Legitimacy in Times of Crisis and Austerity. Edward Elgar Publishing.

[7] Pablo de Pedraza, Martin Guzi, and Kea Tijdens. 2020. Life Dissatisfaction and Anxiety in COVID-19 Pandemic. In GLO Discussion Paper Series 544. Global Labor Organization (GLO).

[8] Donna Evans and David C. Yen. 2006. E-Government: Evolving Relationship of Citizens and Government, Domestic, and International Development. Government Information Quarterly 23, 2 (2006), 207 - 235.

[9] Caitlin Grover. 2016. e-Petitions. Technical Report 1. 2204-4752. Parliament Library \& Information Service, Parliament of Victoria.

[10] Loni Hagen, Teresa M Harrison, Özlem Uzuner, William May, Tim Fake, and Satya Katragadda. 2016. e-Petition Popularity: Do Linguistic and Semantic Factors Matter? Government Information Quarterly 33, 4 (2016), 783-795.

[11] Andreas Jungherr and Pascal Jürgens. 2010. The Political Click: Political Participation through e-Petitions in Germany. Policy \& Internet 2, 4 (2010), 131-165.

[12] Simon Kemp. 2020. Digital 2020: Azerbaijan. (2020). https://datareportal.com/ reports/digital-2020-azerbaijan.

[13] Dmytro Khutkyy. 2019. e-Participation Waves: A Reflection on the Baltic and the Eastern European Cases. EGOV-CeDEM-ePart 2019197 (2019).

[14] Dmytro Khutkyy. 2019. Electronic Democracy in Belarus, Moldova, and Ukraine. Patterns and Comparative Perspectives. Südosteuropa 67, 2 (2019), 264-284.

[15] Ruth Kricheli, Yair Livne, and Beatriz Magaloni. 2011. Taking to the streets: Theory and evidence on protests under authoritarianism. In APSA 2010 Annual Meeting Paper.

[16] Onnik Krikorian, Alexey Sidorenko, and Arzu Geybullayeva. 2010. The Internet in the South Caucasus. Caucasus Analytical Digest (CAD) 15 (2010).

[17] Gustav Lidén. 2015. Technology and Democracy: Validity in Measurements of e-Democracy. Democratization 22, 4 (2015), 698-713.

[18] Ralf Lindner and Ulrich Riehm. 2011. Broadening participation through epetitions? An empirical study of petitions to the German parliament. Policy \& Internet 3, 1 (2011), 1-23.

[19] Giles Moss and Stephen Coleman. 2014. Deliberative manoeuvres in the digital darkness: E-Democracy policy in the UK. The British fournal of Politics and International Relations 16, 3 (2014), 410-427.

[20] Michael Parent, Christine A Vandebeek, and Andrew C Gemino. 2005. Building citizen trust through e-government. Government Information Quarterly 22, 4 (2005), $720-736$. 
[21] Alexander Ronzhyn. 2016. The Analysis of the Technological Platforms for EParticipation in Transition Economies of Ukraine and Russia. Available at SSRN 3002536 (2016)

[22] Jan-Hinrik Schmidt and Katharina Johnsen. 2014. On the use of the e-petition platform of the German Bundestag. HIIG Discussion Paper Series.

[23] Barney Tan, Evelyn Ng, and Junhui Jiang. 2018. The process of Technology Leapfrogging: Case analysis of the national ICT infrastructure development journey of Azerbaijan. International fournal of Information Management 38, 1
(2018), 311 - 316. https://doi.org/10.1016/j.ijinfomgt.2017.10.008

[24] Maarja Toots. 2019. Why E-participation systems fail: The case of Estonia's Osale. ee. Government Information Quarterly 36, 3 (2019), 546-559.

[25] Robert K Yin. 2017. Case Study Research and Applications : Design and Methods, 6xt ed. SAGE.

[26] Seok Yoon. 2019. Azerbaijan: Country Digital Development Overview. (2019).

[27] Farhad Yusifov and Aynur Gurbanli. 2018. E-services evaluation criteria: The case of Azerbaijan. Informacijos mokslai 81 (2018), 18-26. 